\title{
Large vessel vasculitis
}

\author{
Ashima Gulati • Arvind Bagga
}

Received: 23 May 2009/Revised: 12 August 2009/Accepted: 12 August 2009/Published online: 17 October 2009

(C) IPNA 2009

\begin{abstract}
Takayasu arteritis is a chronic granulomatous disease of the aorta and its major branches that usually affects women during the second and third decades of life, but it has been reported in young children. This review details the clinical, pathological and radiological features, differential diagnoses and management of the condition, focusing chiefly on the disease in children. The recent definition of Takayasu arteritis is discussed. The condition should be considered in patients with unexplained arterial hypertension or unexplained inflammatory syndromes without signs of localization. Since the disease may be life-threatening and progressive, early recognition is necessary to initiate appropriate therapy. Patients with persistent ischaemic symptoms including hypertension might benefit from revascularization procedures.
\end{abstract}

Keywords Hypertension · Idiopathic aorto-arteritis ·

Takayasu arteritis

\section{Introduction}

The term 'large vessel vasculitis' encompasses the spectrum of primary vasculitis that causes chronic granulomatous inflammation predominantly of the aorta and its major branches. The two major categories of large vessel vasculitis are temporal (giant cell) arteritis and Takayasu arteritis (TA). These arteritides differ in the age of onset, with the former rarely occurring before the age of 50 years

\footnotetext{
A. Gulati $\cdot$ A. Bagga $(\bowtie)$

Division of Nephrology, Department of Pediatrics,

All India Institute of Medical Sciences,

Ansari Nagar,

New Delhi 110029, India

e-mail: arvindbagga@hotmail.com
}

and the latter rarely after 50 years. The classification system for childhood vasculitides recently published under the auspices of the European League against Rheumatism (EULAR) and the Pediatric Rheumatology European Society (PRES) includes TA as the only form of large vessel vasculitis in childhood [1].

TA is an inflammatory and stenotic disease of mediumand large-sized arteries and is characterized by a predilection for the aortic arch and its branches, hence also referred to as the aortic arch syndrome. While the precise pathogenesis is unknown, intimal fibroproliferation of the aorta, great vessels, pulmonary arteries and renal arteries results in segmental stenosis, occlusion, dilatation and aneurysm formation in these vessels. An alternate term, idiopathic or non-specific aortoarteritis has been used to describe the spectrum of vascular abnormalities associated with the condition.

\section{History}

While an Italian pathologist, Giovanni Battista Morgagni, is credited with the first report of a patient in 1761 [2], the first detailed description was by Savory (1856), who described a 22-year-old woman with seizures, unilateral blindness, scalp ulcerations and pulseless vessels in the head, neck, and upper extremities. At postmortem examination, inflammatory thickening of the aorta and major arteries was identified [3]. At the Annual Meeting of the Japanese Ophthalmology Society in 1908, a Japanese ophthalmologist, Mikito Takayasu, described ocular arterial changes and the association of retinal arteriovenous anastomoses and absent upper extremity pulses [4]. Shimizu and Sano proposed the term 'pulseless disease' in 1951 to describe the triad of: (a) absent radial pulsation, (b) signs 
and symptoms referable to hyperactive carotid sinus reflex, (c) hypotensive ophthalmoangiopathy [5]. Over the past two decades, various expert groups, including the American College of Rheumatology and the Chapel Hill International Consensus Conference, have endorsed the use of the term 'Takayasu arteritis' to describe the condition $[6,7]$.

\section{Epidemiology}

TA is worldwide in distribution, with an incidence of 1.22.6/million per year in the western population and perhaps a 100-times higher incidence in East Asian countries $[8,9]$. The scant number of studies reporting the frequency of TA makes it difficult for one to compare incidence rates.

TA most often affects young women in their second and third decades of life, and the age of onset is usually between 15 and 30 years [10]. The age of onset may vary from infancy $[11,12]$ to middle age. In a series of 60 patients with TA at the National Institute of Allergy and Infectious Diseases in North America, 30\% were younger than 20 years at diagnosis [10].

Women with TA outnumber men by $8-9: 1$. Female patients $(97 \%)$ were most frequently affected in a series of patients from North American [10]. A similar gender predilection has been observed in various reports for children, including those from India and South Africa, which report a female-to-male ratio of 2:1 [13,14].

\section{Pathology}

Histological specimens are seldom available, with the exception of specimens obtained during autopsy and bypass surgery. The vascular pathology in TA is characterized by segmental and patchy granulomatous inflammation of all three layers of the aorta and major branches (Fig. 1). This inflammation leads to arterial stenosis, thrombosis and aneurysms. Mononuclear infiltration of the adventitia with perivascular cuffing of the vasa vasorum occurs early. Granulomatous changes may be observed in the tunica media with Langerhans cells and central necrosis of elastic fibres and smooth muscle cells. Later, fibrosis of the media and acellular thickening of the intima may compromise the vessel lumen. The corresponding organ shows ischaemic changes, which largely determine the clinical features of the disease.

\section{Renal involvement}

The commonest glomerular lesions in TA are non-specific ischaemic changes such as collapsed and/or hyalinized tuft resulting from arterial narrowing or long-standing

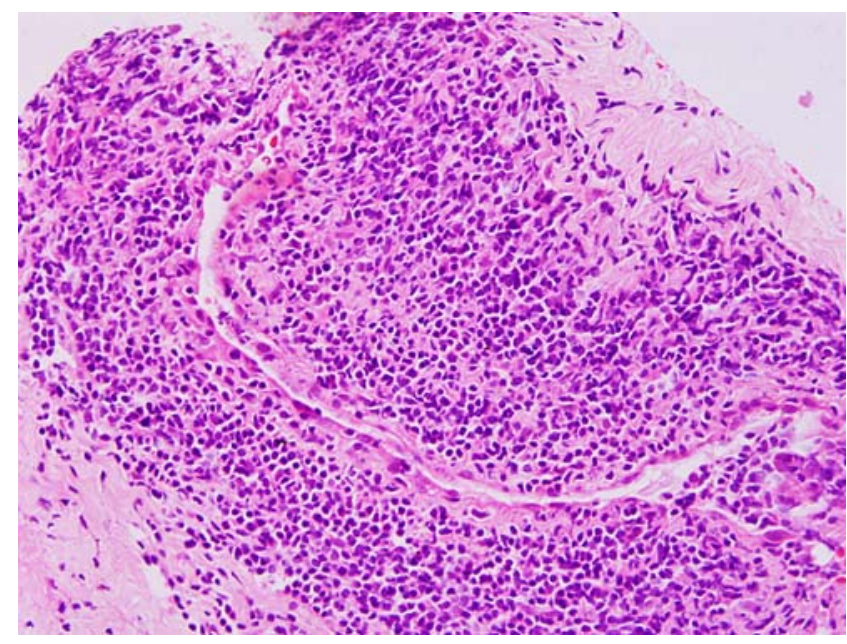

Fig. 1 Photomicrograph (light microscopy) showing transmural inflammation of the vessel wall

renovascular hypertension. Isolated case reports show varied histological features, including immunoglobulin A (IgA) nephropathy, membranoproliferative glomerulonephritis (GN), crescentic GN and mesangioproliferative GN [15-17]. TA complicated by secondary amyloidosis has been reported, with and without evidence of intercurrent tuberculosis [18].

\section{Pathophysiology}

The precise factor(s) responsible for the arterial damage in TA are unknown. The presence of hypergammaglobulinaemia, circulating antibodies against aorta and arteries, circulating immune complexes and a favourable response to steroids suggest the pathogenic role of autoimmunity. It is believed that genetically linked immune responses to unidentified antigen(s) may incite autoimmune damage by cell-mediated or humoral pathways, resulting in the disease and its relapses [19, 20].

Autoantibodies against aortic endothelial cells have been proposed as a key factor in the pathogenesis of TA. Immunoglobulins (Igs) G, M and properdin are found in lesions from pathology specimens. Chauhan et al. reported that patients with TA show circulating anti-aortic endothelial cell antibodies (AAECAs) directed against $60-65 \mathrm{kDa}$ heat-shock proteins (HSPs 60/65) [21]. Sera from AAECApositive patients with TA were found to induce apoptosis of aortic endothelial cells, suggesting that these antibodies have a role in the pathogenesis. There is, however, no direct evidence that AAECAs trigger the development of TA, and it is possible that these autoantibodies are produced secondary to enhanced expression of HSPs $60 / 65$ in aortic vascular cells, which has been induced by other mechanisms. The association of TA with perinuclear and cytoplasmic antineutrophilic cytoplasmic antibodies (ANCAs) also 
suggests a role of these autoantibodies in the pathogenesis of the disease [22]. Case reports describing the association of TA with rheumatoid arthritis, ulcerative colitis, systemic lupus, Crohn disease, sarcoidosis and amyloidosis also emphasize the importance of immune mechanisms in the pathogenesis $[23,24]$.

Although many studies have proposed that bacteria and viruses might have a causative role in primary vasculitides, no specific infectious agents have been identified [20]. This is also supported by the fact that corticosteroids are highly effective, even in the acute inflammatory phase, while, in infection-induced inflammatory diseases such as viral myocarditis, corticosteroid therapy is associated with the risk of aggravation of the inflammation.

While previous reports have suggested the association of TA with tuberculosis, further studies have not supported this association [25]. Although TA is common in the parts of the world with high incidences of tuberculosis, exceptions such as Japan are intriguing. A proposed hypothesis for the pathogenesis of granulomatous vasculitis suggests that antigens deposited in vascular walls activate CD4+ $\mathrm{T}$ cells, release of cytokines, and monocyte chemotaxis. These monocytes are transformed into macrophages that mediate endothelial damage and result in granuloma formation in the vessel walls. Seko showed that injection of syngeneic $\mathrm{T}$ cells sensitized to vascular smooth muscle cells in mice incites granulomatous vasculitis of the pulmonary arterioles [26].

An increased incidence of skin hypersensitivity to the purified protein derivative (PPD) has been reported in patients with TA [27]. HSP-65 is an important antigen of Mycobacterium tuberculosis, Bacillus Calmette-Guérin (BCG) vaccine and many other bacterial species and is synthesized by tissues in response to stress. There is increasing evidence that HSP-65 may be an important antigen inciting immune damage in TA [28, 29]. Crossreactivity between HSP-65 and human leukocyte antigens (HLAs) class II molecules has been described, and expression of HSP-65 and HLA classes I and II antigens is markedly increased in affected aortic tissue [30]. It is speculated that type IV hypersensitivity to PPD is a response to the HSP and is not attributable to past or current infection with M. tuberculosis. The precise association of TA with tuberculosis is unclear, and the condition of patients with TA does not improve following antituberculosis therapy.

\section{Genetic susceptibility}

Genetic susceptibility to the disease has been studied extensively. The condition has been reported in identical twins, leading to a hypothesis for a hereditary basis [31]. In Japan and Korea, TA is associated with HLA A10, B5,
Bw52, DR2 and DR4 [32, 33]. Kasuya et al. showed that association of TA with HLA Bw52 results in higher incidence of coronary artery and myocardial involvement and a worse prognosis [33]. TA is associated with HLA B22 in the United States of America [34] and with HLA B5 and B21 in Indian patients [35].

\section{Clinical features}

The clinical features of TA are divided into an early prepulseless systemic phase and a late occlusive phase. Approximately half of all patients show the difficult-todiagnose early phase, characterized by nonspecific features such as low-grade fever, malaise, night sweats, weight loss, arthralgia and fatigue [5]. There is often anaemia and marked elevation of the erythrocyte sedimentation rate (ESR). This active phase may remit spontaneously in about 3 months or it may progress insidiously into the chronic phase, characterized by inflammatory and obliterative changes in the aorta and its branches [10]. In this late occlusive phase of the disease, characteristic features of TA appear, which include diminished or absent pulses, vascular bruits, hypertension (as a consequence of renal artery stenosis), mesenteric angina, retinopathy, aortic regurgitation (when the ascending aorta is involved) and neurological symptoms secondary to hypertension or ischaemia (postural dizziness, seizures, amaurosis). Weakness of the arterial walls may give rise to localized aneurysms. A history of Raynaud phenomenon may be present [20]. The frequency of arteriographic abnormalities in TA and consequent clinical manifestations are illustrated in Table 1.

This sequential presentation is, however, likely to occur only in a minority of patients, because the disease is usually recurrent, leading to coexistence of various phases. Further, there can be activity during the chronic illness, not all patients manifest an acute phase, and some may present in chronic phase only. A variable interval (months to years) may separate acute from occlusive phases, during which vascular insufficiency develops. Glomerular damage in TA is manifested by microscopic haematuria and nonnephrotic-range proteinuria. The presentation of nephrotic syndrome is uncommon, except in those with complicating amyloidosis.

\section{Ethnic differences}

A review of clinical features in TA shows geographical variations based on the site of vascular involvement. Hata et al. evaluated the angiographic findings of 80 Japanese patients and 102 Indian patients with TA. Patients from Japan showed a high frequency of involvement of the ascending aorta, aortic arch and its branches, while involvement of the abdominal aorta and renal arteries was 
Table 1 Frequency of arteriographic abnormalities and potential clinical features of arterial involvement (Kerr et al. [10])

\begin{tabular}{lll}
\hline Artery & Abnormalities (\%) & Potential manifestations \\
\hline Subclavian & 93 & Arm claudication, Raynaud phenomenon \\
Common carotid & 58 & Visual changes, syncope \\
Abdominal aorta & 47 & Abdominal pain \\
Renal & 38 & Hypertension, renal failure \\
Aortic arch & 35 & Aortic insufficiency \\
Vertebral & 35 & Visual changes \\
Coeliac axis & 18 & Abdominal pain \\
Pulmonary & 20 & Chest pain, dyspnoea \\
\hline
\end{tabular}

significantly greater in Indian patients [36]. In another series from India, in children and young adults, the abdominal aorta was the commonest vessel affected [13]. In North American children with TA, lesions of the thoracic and abdominal aorta, rather than that of the aortic arch, are common [9]. It is not known whether these variations reflect differing causes of TA. However, all patterns of vascular involvement are observed in every region.

Takayasu arteritis in children

Systemic symptoms are seen in a high proportion (60-70\%) of children with TA. The usual presenting symptoms are due to hypertension, heart failure or a neurological event. Claudication, bruit or a missing pulse in an asymptomatic child are uncommon presentations. TA is considered to be the commonest cause of renovascular hypertension in Asian children [37].

The largest paediatric series reported by Hong et al. [38] describes 70 patients, the youngest being 3 years old. Hypertension was the usual presentation seen in $93 \%$ of cases. In a report on 31 patients from South Africa, arterial hypertension was the chief feature, followed by cardiac failure, bruits and absent pulses [14]. A report on 24 patients from India described arterial hypertension in $83 \%$, congestive heart failure in $16 \%$ and left ventricular hypertrophy in 54\% [13]. In a Turkish multicentre review, TA represented $1.5 \%$ of the vasculitides in children. The majority (71.4\%) had constitutional symptoms, and hypertension was found in $86 \%$ [39]. Hypertension is not only the most common clinical presentation, but is often the sole manifestation of TA in children [40, 41].

A review of clinical and radiological features based on the published reports in children with TA is shown in Table 2.

\section{Diagnostic criteria}

The diagnosis of TA is often delayed because of nonspecific clinical symptoms. The Ishikawa criteria [42], widely used for diagnosis, are based on observations in Japanese patients and consist of obligatory, major and minor criteria. The obligatory criterion is age less than 40 years at diagnosis or at onset of characteristic signs and symptoms of 1 month's duration. The major criteria are involvement of the right or left mid-subclavian artery, and the minor criteria include raised ESR, carotid artery tenderness, hypertension, aortic regurgitation, pulmonary artery lesions and involvement of the common carotid, brachiocephalic, descending thoracic aorta or abdominal aorta. In addition to the obligatory criterion, the presence of two major criteria, or one major and two or more minor criteria, or four minor criteria, suggests a high probability of the presence of TA [42]. These criteria have greater sensitivity for patients with active disease than for those with inactive disease. Geographic variations in the pattern of arterial involvement may reduce the sensitivity of these criteria.

Modifications have been proposed in Ishikawa's criteria for the diagnosis [43]. The proposed modifications include removal of the obligatory criterion of age less than 40 years, inclusion of characteristic signs and symptoms as a major criterion, deletion of the absence of an aorto-iliac lesion in defining abdominal aortic lesion, and addition of coronary artery lesion. The modified proposal consists of three major criteria (including left and right mid-subclavian artery lesions, and characteristic signs and symptoms of at least 1 month's duration) and ten minor criteria (high erythrocyte sedimentation rate, carotid artery tenderness, hypertension, aortic regurgitation or annulo-aortic ectasia, pulmonary artery lesion, left mid-common carotid lesion, distal brachiocephalic trunk lesion, descending thoracic aorta lesion, abdominal aorta lesion and coronary artery lesion). The presence of two major criteria, or one major and two minor criteria, or four minor criteria, suggests a high probability of TA [43].

When applied to 106 Indian and 79 Japanese patients with angiographically proven TA, the above criteria had a sensitivity and specificity that were greater than those of the Ishikawa and American College of Rheumatology (ACR) 
Table 2 Summary of clinical and radiological findings in studies on Takayasu arteritis in children. The values represent actual numbers. Dashes indicate that data were not available

\begin{tabular}{|c|c|c|c|c|c|c|c|c|}
\hline \multirow[t]{2}{*}{ Authors } & \multirow[t]{2}{*}{ Number } & \multirow[t]{2}{*}{ Male } & \multirow{2}{*}{$\begin{array}{l}\text { Constitutional } \\
\text { symptoms }\end{array}$} & \multirow[t]{2}{*}{ Hypertension } & \multicolumn{3}{|c|}{ Radiological involvement } & \multirow{2}{*}{$\begin{array}{l}\text { Number of } \\
\text { deaths }\end{array}$} \\
\hline & & & & & $\begin{array}{l}\text { Renal } \\
\text { artery }\end{array}$ & $\begin{array}{l}\text { Abdominal } \\
\text { aorta }\end{array}$ & $\begin{array}{l}\text { Thoracic } \\
\text { aorta }\end{array}$ & \\
\hline Hong et al. [38] & 70 & 13 & - & 65 & - & - & - & - \\
\hline Hahn et al. [14] & 31 & 13 & 2 & 27 & 26 & 22 & 11 & 7 \\
\hline Jain et al. [13] & 24 & 4 & - & 20 & 18 & 17 & 5 & - \\
\hline Ozen et al. [39] & 14 & 7 & 10 & 12 & 12 & 14 & 7 & 1 \\
\hline $\mathrm{Al}$ abrawi et al. [41] & 4 & 2 & 2 & 2 & 2 & 1 & 1 & - \\
\hline $\begin{array}{l}\text { Shrivastava et al. } \\
{[40]}\end{array}$ & 47 & 20 & 20 & 34 & 35 & 47 & - & 4 \\
\hline $\begin{array}{l}\text { Dabague and Reyes } \\
\text { [70] }\end{array}$ & 55 & 12 & 35 & 49 & - & - & - & - \\
\hline
\end{tabular}

criteria [43]. Adoption of these criteria is expected to prevent the possibility of under-diagnosis of TA. The ACR criteria were developed from the comparison of 63 patients with TA with 744 controls with other forms of vasculitis, and six criteria were selected for classifying patients as having TA [6] (Table 3).

In 2005 a consensus conference on childhood vasculitis, under the auspices of the EULAR and the PRES, proposed diagnostic criteria for various vasculitides that differ in some respects from the ACR classification criteria. This classification suggested the inclusion of hypertension as a criterion for childhood TA, since this was often the only presenting sign of the disease (Table 4) [1]. A prospective validation of the proposed classification criteria was recently reported on 87 children with TA enrolled from 97 centres in 36 countries. The sensitivity and specificity of the new criteria were $100 \%$ and $99 \%$, respectively, with a kappa agreement of 0.99 between the consensus panel and the proposed definition. The sensitivity of the ACR criteria, in this cohort, was lower, at $79 \%$; specificity was $100 \%$, and the kappa score was 0.84. The EULAR/PRES definition, therefore, has a high sensitivity and specificity for the classification of TA [44].

\section{Laboratory evaluation}

No specific serum markers for TA have been identified. Complete blood count shows normochromic normocytic anaemia (in 50\% of patients), leukocytosis and thrombocytosis. Concentrations of acute phase reactants, including C-reactive protein and the ESR, correlate

Table 3 American College of Rheumatology criteria for the classification of Takayasu arteritis [6]

\begin{tabular}{|c|c|}
\hline Criterion & Definition \\
\hline $\begin{array}{l}\text { Age of patient at disease onset } \\
\text { in years }\end{array}$ & Development of symptoms or findings related to Takayasu arteritis at age $<40$ years \\
\hline Claudication of extremities & $\begin{array}{l}\text { Development and worsening of fatigue and discomfort in muscles of one or more extremity while in use, } \\
\text { especially the upper extremities }\end{array}$ \\
\hline $\begin{array}{l}\text { Decreased brachial artery } \\
\text { pulse }\end{array}$ & Decreased pulsation of one or both brachial arteries \\
\hline $\begin{array}{l}\text { Blood pressure difference } \\
>10 \mathrm{mmHg}\end{array}$ & Difference of $>10 \mathrm{mmHg}$ in systolic blood pressure between arms \\
\hline $\begin{array}{l}\text { Bruit over subclavian arteries } \\
\text { or aorta }\end{array}$ & Bruit audible on auscultation over one or both subclavian arteries or abdominal aorta \\
\hline Arteriogram abnormality & $\begin{array}{l}\text { Arteriographic narrowing or occlusion of the entire aorta, its primary branches, or large arteries in the proximal } \\
\text { upper or lower extremities, not due to arteriosclerosis, fibromuscular dysplasia, or similar causes; changes are } \\
\text { usually focal or segmental }\end{array}$ \\
\hline
\end{tabular}

Takayasu arteritis is classified if at least three of the six criteria are present. The presence of three or more criteria yields a sensitivity of $90.5 \%$ and a specificity of $97.8 \%$ 
Table 4 EULAR classification criteria for Takayasu arteritis [1] (CT computed tomography, MRI magnetic resonance imaging, ESR erythrocyte sedimentation rate, $C R P$ C-reactive protein)

\begin{tabular}{ll}
\hline Requirement & Description \\
\hline Mandatory criterion & Angiographic abnormalities (conventional, CT or MRI) of the aorta or its major branches \\
Plus one of these five criteria & Pulse deficit or claudication of the extremities \\
& Blood pressure discrepancy in four limbs $(>10 \mathrm{mmHg})$ \\
& Bruit over the aorta and/or its major branches \\
& Systolic/diastolic hypertension $>95$ th centile for height \\
& Elevated acute phase reactants (ESR or CRP) \\
\hline
\end{tabular}

Takayasu arteritis is diagnosed if at least one of the five criteria is present, together with the mandatory criterion

poorly with disease activity. Some patients show elevated transaminase levels, hypoalbuminaemia and hypergammaglobulinaemia [10]. The concentration of von Willebrand factor-related antigen may be elevated. Anti-endothelial cell antibodies are often present, and antinuclear antibody is usually negative. Rheumatoid factor is elevated in $15 \%$ of patients [20]

\section{Imaging studies}

Conventional or digital subtraction angiography is considered to be necessary for the diagnosis of TA and its complications. Angiography shows luminal irregularity, vessel stenosis, occlusion, dilatation or aneurysms in the aorta or its primary branches (Figs. 2). The Takayasu Conference (1994) proposed a classification based on angiographic abnormalities [13]:

Type I. Classic pulseless type that affects blood vessels of aortic arch; involving the brachiocephalic trunk, carotid and subclavian arteries.

Type II. Affects middle aorta (thoracic and abdominal aorta).

Type III. Affects aortic arch and abdominal aorta.

Type IV. Affects pulmonary artery in addition to any of the above types.

A fifth type includes patients with involvement of the coronary arteries [13].

Drawbacks to arteriography include the morbidity from use of contrast media in patients with renal disease and the risk of radiation exposure. Recently, computed tomography (CT) and magnetic resonance imaging (MRI) (CT and MR angiography) have been shown to delineate aortic mural changes that are difficult to detect on conventional angiography (Fig. 3). CT scanning and MR angiography may reveal mural thickening of the aorta and luminal narrowing and may detect inflammatory lesions prior to the development of stenoses. Such lesions may be missed on standard angiography.

\section{MRI features of acute phase}

Significant findings in the acute phase of TA are thickening of the wall of the aorta and pulmonary arteries. Noncontrast T2-weighted short inversion images may be used to monitor oedema of the aortic wall, which suggests inflammation in a high proportion of patients with active disease [45]. The thickened aortic wall is enhanced on gadolinium-enhanced images. A recent report suggests that delayed contrast-enhanced MRI may also be a useful technique to identify inflammation in the arterial wall [46]. Some patients may show occlusion or pseudoaneurysm formation of the aortic branches or pulmonary artery in the acute phase.

\section{MRI features of late phase}

Significant findings include diffuse narrowing of the descending thoracic and abdominal aorta and dilatation of the ascending aorta. Cine-MRI may depict aortic regurgitation caused by dilatation of the ascending aorta. Stenotic lesions, typically affecting the proximal portions, of all arteries arising from the aorta and pulmonary artery are seen in the late phase. Occlusion is the second most common finding. Abrupt occlusion, abrupt transition to collateral vessels and flame-shaped termination are characteristic. In the abdominal aorta the renal artery is the most frequently involved branch. Pulmonary artery involvement may also be seen in 50 $80 \%$ of patients.

Thus, MRI is useful in the accurate diagnosis of TA, has a distinct advantage over $\mathrm{CT}$ imaging, and can provide almost all anatomic information needed to enable early treatment. If available, MRI may be the preferred technique 

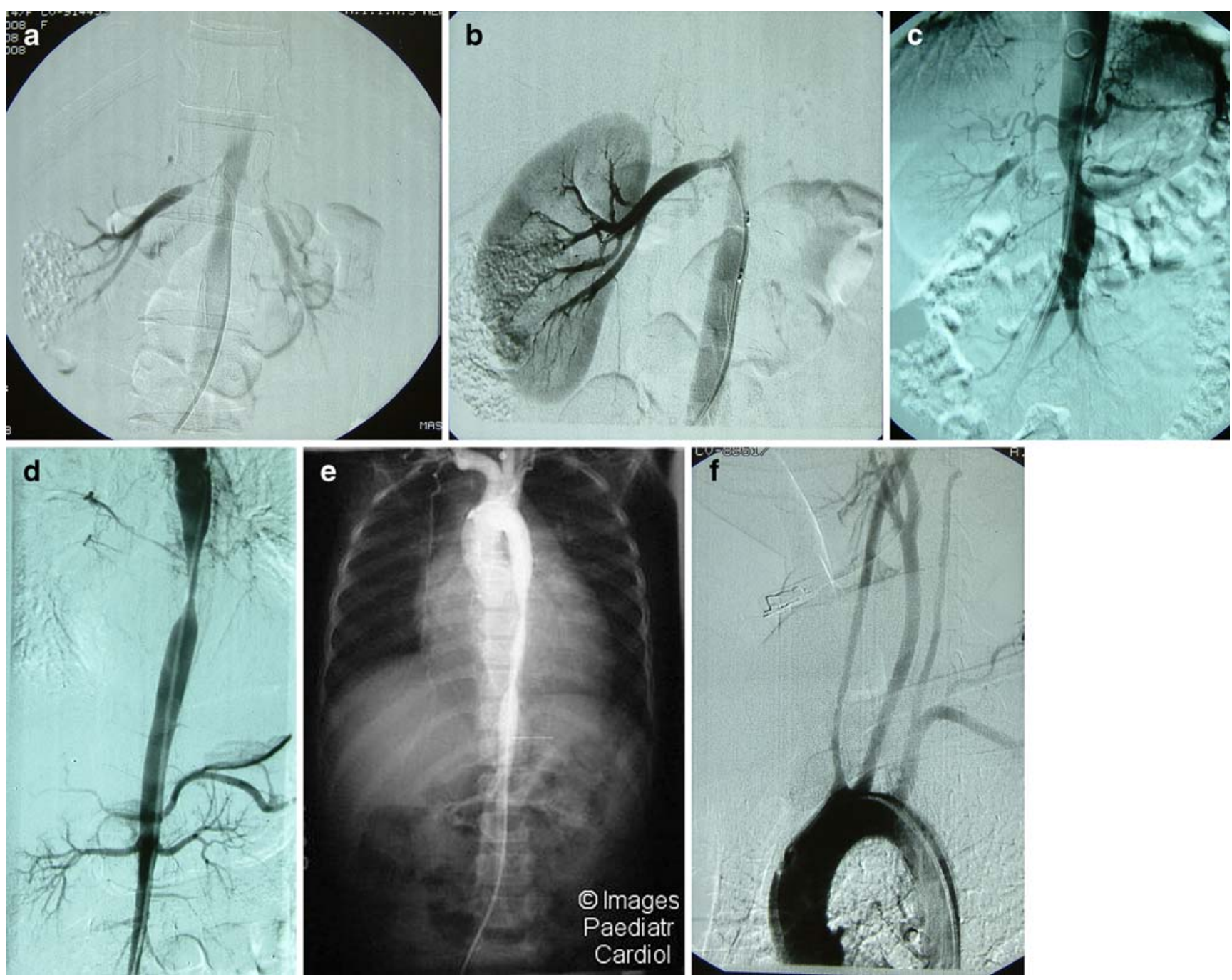

Fig. 2 Digital subtraction angiogram showing a bilateral renal artery stenosis in an 8-year-old girl and (b) right renal artery after dilatation in the same patient. c Juxta-renal aortic involvement with bilateral renal artery stenosis in a 10-year-old girl. d Tight stenosis of the distal descending thoracic aorta in an 8-year-old girl. e Extensive thoraco-

abdominal aortic involvement (with permission). f Bilateral subclavian artery occlusion in a 9-year-old boy. Courtesy of Prof. S. Sharma, Department of Cardiac-Radiology, All India Institute of Medical Sciences, New Delhi

for the diagnosis and monitoring of the course of treatment in patients with TA.

\section{Other imaging studies}

A gallium-67 radionuclide scan may demonstrate increased uptake in the aorta and its branches. While high-resolution ultrasonography has been used to evaluate and monitor disease in the common carotid and subclavian arteries, this study is not useful in evaluating the aorta. Chest radiography may reveal widening of the ascending aorta, irregular descending aorta, aortic calcifications and rib notching. Prominent pulmonary arteries signify pulmonary hypertension, whereas oligaemic lungs suggest involvement of intrapulmonary

arterial branches. In the presence of hilar lymphadenopathy, the possibility of coexistent sarcoidosis should also be considered [47]. Echocardiography should be performed to evaluate the aortic valve and to monitor aortic insufficiency.

\section{Positron emission tomography and biomarkers for assessing disease activity}

2-[Fluorine-18]-fluoro-2-deoxy-D-glucose $\left({ }^{18} \mathrm{~F}-\mathrm{FDG}\right)$ positron emission tomography (PET) is a sensitive imaging method in the assessment of early stages of the disease. Increased FDG uptake by inflammatory cells in the vessel walls allows localization of disease activity and assessment 


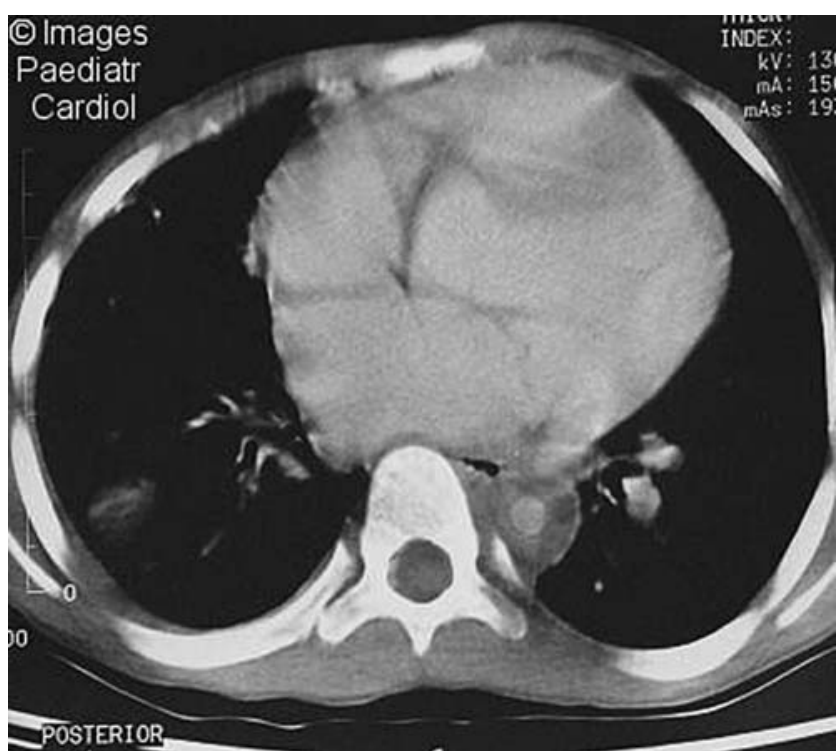

Fig. 3 Contrast-enhanced CT scan showing concentric, thickened, aortic walls of the descending thoracic aorta (with permission)

of vascular morphology in patients with clinical activity [48].

Tripathy et al. studied the cytokine profiles of peripheral blood lymphocytes in patients with TA. Increased percentages of high tumour necrosis factor alpha (TNF- $\alpha)$ - and low interleukin (IL)-2-producing $\mathrm{T}$ cells were found in active TA compared with inactive TA and controls [49]. Patients with TA also show higher numbers of $\gamma \delta$ T-cells than those of healthy controls [50]. Others report that plasma levels of IL-6, IL-12 and IL-18, and metalloprotease 9 correlate with disease activity [51-53].

\section{Differential diagnosis}

In patients who present solely with features that suggest the involvement of large vessels, tissue biopsies are not possible and the diagnosis is made on the basis of characteristic arteriographic changes combined with consistent clinical features. A number of important diseases should be considered in the differential diagnosis. These include acute infections (mycotic aneurysms due to septicaemia or endocarditis), chronic infections [syphilis, tuberculosis, human immunodeficiency virus (HIV), leprosy], congenital causes (aortic coarctation, middle aortic syndrome), hereditary disorders (Marfan syndrome, neurofibromatosis, Ehler-Danlos syndrome), fibromuscular dysplasia and post-radiation therapy. Treatment of these conditions with immunosuppressive agents may be ineffective or may worsen the disease, emphasizing the importance of an accurate diagnosis.

\section{Treatment}

In the absence of knowledge of its precise aetiology, the treatment of TA is based on clinical symptoms and the possible immunological basis of the disease. Randomized controlled treatment trials are either lacking or based on small numbers of patients, making evidence-based management decisions difficult. The goal of treatment is to relieve inflammation in the arteries and prevent potential complications.

\section{Medical therapy}

The indications for medical therapy include:

1. Active and/or early lesions not requiring surgical intervention.

2. Surgery and balloon angioplasty not possible because of associated co-morbidities, e.g. uncontrolled congestive heart failure and progressive renal failure.

\section{Corticosteroids}

While corticosteroids have not been rigorously studied in controlled clinical trials, they are the chief form of medical therapy. In a series from the National Institutes of Health (USA), prednisolone/prednisone was given at a dose of $1 \mathrm{mg} / \mathrm{kg}$ daily for $1-3$ months and later tapered to an alternate-day schedule [10]. Administration of prednisolone improves constitutional symptoms, halts disease progression in active disease and normalizes the ESR. The medication should be tapered to an alternate-day regimen, preferably after 3 months. Since relapses of the disease are common, it is recommended that therapy with corticosteroids be continued for 1 year following clinical remission and then tapered to discontinuation. Most patients require treatment for extended periods.

Indications for alternative therapy

Patients who fail to respond clinically to 3 months' treatment with prednisolone (dose $1 \mathrm{mg} / \mathrm{kg}$ daily) (corticosteroid resistance) or show a flare of the disease on its tapering should be considered for alternative therapy. Since alternative therapy also enables steroid sparing, these medications have an important role in the therapy of children with TA.

\section{Methotrexate}

An open-label study showed the beneficial effect of methotrexate in 16 patients with TA and corticosteroid 
resistance. Methotrexate was used at a low dose of $0.3 \mathrm{mg} / \mathrm{kg}$ per week (not to exceed $15 \mathrm{mg} /$ week), increasing every $1-2$ weeks to $25 \mathrm{mg} /$ week with prednisolone at $1 \mathrm{mg} / \mathrm{kg}$ daily. Combined therapy resulted in remission rates of $81 \%$; of those patients for whom remission of the disease was achieved, $50 \%$ had sustained remissions of 4-34 (mean 18) months [54].

\section{Cyclophosphamide}

Of six patients with clinical or angiographic progression of vasculitis on daily steroid therapy who were administered cyclophosphamide ( $2 \mathrm{mg} / \mathrm{kg}$ per day) orally, no progression of vascular lesions occurred in four. Two patients showed progressive vascular lesions after 30 months and 48 months of therapy [55]. A single-centre experience from Turkey suggests that induction with cyclophosphamide and corticosteroids is an effective and safe treatment for children with TA. In three of the four patients that had received cyclophosphamide (maximum total dose $150 \mathrm{mg} / \mathrm{kg}$ ) with prednisolone for 12-18 months, the disease entered remission [56]. Intravenous treatment with cyclophosphamide has also been reported to confer benefit [57]. Despite limited therapeutic data, treatment with cyclophosphamide should be considered for patients with life-threatening manifestations.

\section{Mycophenolate mofetil}

Mycophenolate mofetil (MMF) has been used increasingly as an alternative medication for patients with TA. Shinjo et al. followed ten consecutive patients with active TA who received oral treatment with MMF (at a dose of $2 \mathrm{~g} /$ day) for a mean duration of 23.3 months together with tapering doses of prednisolone. Clinical activity resolved in all patients, except in one who withdrew from the study because of headache, attributed to the medication [58]. Therapy with MMF allowed tapering of the corticosteroid dose in nine patients and significant reduction in ESR and Creactive protein. Treatment with $\mathrm{MMF}$ is a promising alternative to steroids and cytotoxic agents. However, until results of controlled trials become available, this therapy should be considered as a steroid-sparing one for patients with refractory disease that does not improve with corticosteroid therapy [59].

Other agents that were examined in few patients as alternative therapy include azathioprine and cyclosporine $[60,61]$ and infliximab (TNF- $\alpha$ receptor blocker) [62]. Hoffman et al. report the results of an open-label, multicentric, study on anti-TNF- $\alpha$ therapy in 15 patients with TA whose condition had failed to respond to corticosteroid or alternative immunosuppressive therapies. Treatment with infliximab resulted in clinical improvement for 14 patients and sustained remission for ten, who were able to discontinue glucocorticoid therapy [63]. While initial results are promising, the role of TNF inhibition in treating initial disease or relapses of TA has not been established.

Given a role of matrix metalloproteinases (MMPs) in the pathogenesis of TA [64], their inhibition by minocycline has been proposed as a useful adjunctive therapy. Therapy with minocycline and oral administration of corticosteroids in patients with active TA resulted in a significant decrease in C-reactive protein, ESR and clinical disease activity, in association with reduced blood levels of MMP-3 and MMP-9.

Patients with systemic hypertension and/or congestive heart failure require appropriate therapy. Renovascular hypertension responds poorly to drug therapy. The efficacy of treatment with oral anticoagulants, antiplatelet agents and vasodilators has not been established. Sildenafil may be useful for patients with peripheral vascular compromise, such as digital ischaemia [65]. There is no role for empirical therapy with antituberculosis medications, unless there is clear documentation of associated tubercular disease.

\section{Revascularization procedures}

The definitive treatment of occlusive disease is surgical. Surgical treatment should be considered for patients with progressive TA, particularly in the absence of a response to conventional therapy, in order to prevent complications.

The indications for surgical treatment are:

1. Hypertension from stenotic coarctation of the aorta or renovascular disease.

2. End organ ischaemia or peripheral limb ischaemia.

3. Cerebral ischaemia.

4. Aortic or arterial aneurysms, or aortic regurgitation.

Surgery during the active phase of the disease carries significant risk of re-occlusion and procedural complications. Surgical treatment should be delayed until the acute phase is over. Revascularization techniques for TA include: (a) surgical bypass grafting, (b) patch angioplasty for shortsegment lesion, (c) endarterectomy, (d) percutaneous transluminal angioplasty (PCTA) and (e) vascular stenting.

PCTA can achieve high rates of initial success, as reported by Sharma et al. (initial success rate of $82 \%$ for 33 patients with renal artery lesions) and Tyagi et al. (initial success rate of $89 \%$ and patency rate of $79 \%$ at mean follow up of 43 months for 45 patients) [66, 67]. The success rate was lower at $56 \%$ in the National Institutes of Health (NIH) cohort of 11 patients; complications including restenosis in $45 \%$ procedures [10]. Data from the Cleveland clinic also showed restenosis in $78 \%$ of the procedures, 
which were initially successful [68]. Although PTCA can achieve high rates of initial success in TA, the long-term results are less satisfactory.

Endovascular stenting has been used in patients with severe stenosis and hypertension or ischaemia during the fibrotic phase of the disease. Multiple stents have been used in children to relieve long-segment renal artery stenosis and attendant renovascular hypertension. Bypass/reconstruction procedures in TA have shown better sustained patency than that by PCTA, but long-term results report patency rates of $33 \%$ at 2 years [69]. In the NIH cohort, in 50 bypass procedures, $24 \%$ of the patients had restenosis and $4 \%$ suffered bypass graft thrombosis [10].

\section{Outcome}

Before the availability of sequential vascular imaging, TA was perceived as a relatively benign disease that eventually 'burned out' in most patients [70]. However, longitudinal imaging data from the NIH and the Cleveland clinic confirm that most patients experience new lesions over time $[10,68]$. One common finding in TA is the persistence of vascular inflammation in patients whose condition appears to be clinically silent. Surgical specimens from patients in whom the disease is in clinical remission have revealed histological evidence of vasculitis in $>40 \%$ of cases [71]. Thus, most patients have a disease that is chronic or relapsing in nature.

TA can be associated with significant morbidity, and the likelihood of disability correlates with the number of disease relapses [68]. Aortic valve insufficiency and congestive heart failure are reported in $25 \%$ of patients $[10,68]$ and vascular claudication sufficient to limit routine activities in up to $40 \%$ of patients $[10,70]$. The chief causes of death include congestive heart failure, myocardial infarction, aneurysm rupture or renal failure $[69,72]$. Lupi-Herrera et al. report a $15 \%$ mortality rate among patients with TA; most deaths were attributed to heart failure [69]. A cohort of 88 patients from India showed a 5-year and 10-year survival rate of $91 \%$ and $84 \%$, respectively [72].

While long-term follow-up data are scant, TA in children is a serious illness, and a mortality rate of $10-30 \%$ has been reported on follow up. In a series of 26 Mexican children aged 3-15 years, the 5-year survival rate was 35\% [70]. The presence of severe vasculitis (defined as the presence of severe grades of hypertension, aortic regurgitation, retinopathy or aneurysms) and poor functional class or cardiac involvement predict a poorer outcome. Although glucocorticoid therapy alleviates symptoms, there are no convincing studies that show that they increase survival. While the prognosis for TA has improved, due to interventional vascular procedures, unremitting disease activity can lead to unsatisfactory outcomes. Further, high rates of restenosis following vascular interventional procedures reinforce recommendations to try to postpone surgeries until the TA is in remission.

\section{Questions}

(Answers appear following the reference list)

1. The usual age of onset of Takayasu arteritis is:
a. 1-15 years
b. $15-30$ years
c. $30-45$ years
d. $>45$ years

2. Glomerular lesions in Takayasu arteritis include all, except
a. Amyloidosis
b. Mesangioproliferative glomerulonephritis
c. Crescentic glomerulonephritis
d. Membranous nephropathy

3. All of the following are true of Takayasu arteritis, except

a. Evidence of hypersensitivity to purified protein derivative (PPD) of mycobacteria

b. Association with specific HLA types

c. Predominant involvement of the aortic arch and its branches in patients from the Indian subcontinent

d. Presence of congestive heart failure is associated with unfavourable outcome

4. A 10-year-old girl has Takayasu arteritis with ostial renal artery stenosis, grade II hypertension and left ventricular hypertrophy. Therapy that is likely to be most effective is:

a. Combination antihypertensive therapy

b. Prednisolone, mycophenolate mofetil

c. Percutaneous angioplasty

d. Autotransplantation

\section{References}

1. Ozen S, Ruperto N, Dillon MJ, Bagga A, Barron K, Davin JC, Kawasaki T, Lindsley C, Petty RE, Prieur AM, Ravelli A, Woo P (2006) EULAR/PRES endorsed consensus criteria for the classification of childhood vasculitides. Ann Rheum Dis 65:936-941

2. Lazzarin P, Pasero G, Marson P, Cecchetto A, Zanchin G (2005) Takayasu's arteritis. A concise review and some observations on a putative case reported by Giovanni Battista Morgagni (1761). Reumatismo 57:305-313

3. Savoy WE (1856) Case of a young woman in whom the main arteries of both upper extremities and of the left side of the neck were throughout completely obliterated. Med Chir Transact 39:205-219 
4. Takayasu M (1908) A case with peculiar changes of the central retinal vessels. Acta Soc Ophthalmol Jpn 12:554

5. Sano K (2008) Takayasu disease - pulseless disease. Brain Nerve 60:31-35

6. Arend WP, Michel BA, Bloch DA, Hunder GG, Calabrese LH, Edworthy SM, Fauci AS, Leavitt RY, Lie JT, Lightfoot RW Jr, Mas AT, McShane DJ, Mills JA, Stevens MB, Wallace SL, Zvaifler NJ (1990) The American College of Rheumatology 1990 criteria for the classification of Takayasu arteritis. Arthritis Rheum $33: 1129-1134$

7. Jennette JC, Falk RJ, Andrassy K, Bacon PA, Churg J, Gross WL, Hagen EC, Hoffman GS, Hunder GG, Kallenberg CGM, McCluskey RT, Sinico RA, Rees AJ, van Es LA, Waldherr R, Wiik A (1994) Nomenclature of systemic vasculitides. Proposal of an international consensus conference. Arthritis Rheum 37:187192

8. Johnston SL, Lock RJ, Gompels MM (2002) Takayasu arteritis: a review. J Clin Pathol 55:481-486

9. Hall S, Barr W, Lie JT, Stanson AW, Kazmier FJ, Hunder GG (1985) Takayasu arteritis: a study of 32 North American patients. Medicine (Baltimore) 64:89-99

10. Kerr CS, Hallahan CW, Giordano J, Leavitt RY, Fauci AS, Rottem M, Hoffman GS (1994) Takayasu's arteritis. Ann Intern Med 120:919

11. Eke F, Balfe JW, Hardy BE (1984) Three patients with arteritis. Arch Dis Child 59:877-883

12. Ladhani S, Tulloh R, Anderson D (2001) Takayasu disease masquerading as interruption aorta in a 2 years old child. Cardiol Young 11:244-246

13. Jain S, Sharma N, Singh S, Bali HK, Kumar L, Sharma BK (2000) Takayasu arteritis in children and young Indians. Int J Cardiol 75:53-57

14. Hahn D, Thomson PD, Kala U, Beale PG, Levin SE (1998) A review of Takayasu arteritis in children in Gauteng, South Africa. Pediatr Nephrol 12:668-675

15. Korzets Z, Barenboim E, Bernheim J, Mekori Y, Bernheim J (1998) Mesangioproliferative glomerulonephritis, antiphospholipid antibodies and Takayasu's arteritis - is there a link? Nephrol Dial Transplant 13:991-993

16. Cavatorta F, Campisi S, Trabassi E, Zollo A, Salvidio G (1995) IgA nephropathy associated with Takayasu's arteritis: report of a case and review of the literature. Am J Nephrol 15:165-167

17. Yoshikawa Y, Truong LD, Mattioli CA, Lederer E (1988) Membranoproliferative glomerulonephritis in Takayasu's arteritis. Am J Nephrol 8:240-244

18. Dash SC, Malhotra KK, Sharma RK, Bhuyan UN (1984) Renal amyloidosis and non-specific aortoarteritis - a hitherto unrecognized association. Postgrad Med J 60:626-628

19. Bahl VK, Seth S (2002) Takayasu arteritis revisited. Indian Heart J 54:147-151

20. Rodriguez-Pla A, Stone H (2006) Vasculitis and systemic infections. Cur Opin Rheumatol 18:39-47

21. Chauhan SK, Tripathy NK, Nityanand S (2006) Antigenic targets and pathogenicity of antiaortic endothelial cell antibodies in Takayasu arteritis. Arthritis Rheum 54:2326-2333

22. Chirinos JA, Corrales VF, Lichtstein DM (2005) ANCAassociated large vessel compromise. Clin Rheumatol 25:111112

23. Hall S, Nelson AM (1986) Takayasu arteritis and juvenile rheumatoid arthritis. J Rheumatol 13:431-432

24. Opastirakul S, Chartapisak W, Sirivanichai C (2004) A girl with Takayasu arteritis with possible systemic lupus erythematosus. Pediatr Nephrol 19:463-466

25. Sen PK, Kinare SG, Kelkar MD, Nanivadkar SA (1972) Nonspecific stenosing arteritis of the aorta and its branches: a study of possible etiology. Mt Sinai J Med 39:221-242
26. Seko Y (2000) Takayasu arteritis. Insights into immunopathology. Jpn Heart J 41:15-26

27. Kothari SS (1995) Aetiopathogenesis of Takayasu's arteritis and BCG vaccination: the missing link? Med Hypotheses 45:227-230

28. Aggarwal A, Chag M, Sinha N, Naik S (1996) Takayasu arteritis: role of Mycobacterium tuberculosis and its $65 \mathrm{kDa}$ heat shock protein. Int J Cardiol 55:49-55

29. Chauhan SK, Tripathy NK, Sinha N (2004) Cellular and humoral immune responses to mycobacterial heat shock protein- 65 and its human homologue in Takayasu's arteritis. Clin Exp Immunol 138:547-553

30. Seko Y, Minota S, Kawasaki A (1994) Perforin secreting killer cell infiltration and expression of $65-\mathrm{KD}$ heat shock protein in aortic tissue of patients with Takayasu's arteritis. J Clin Invest 93:750-758

31. Enomoto S, Magara J, Iwasaki Y, Bannai S, Nara Y, Aizawa Y, Matsuoka A, Shibata A (1983) Aortitis syndrome in a pair of monozygotic twins. Nippon Naika Gakkai Zasshi 72:1553-1556

32. Dong RP, Kimur A, Numenno F, Nashimura Y, Sasazuki T (1992) HLA linked susceptibility and resistance to Takayasu arteritis. Heart Vessels Suppl 7:73-80

33. Kasuya K, Hashimoto Y, Numenno F (1992) Left ventricular dysfunction and HLA Bw52 antigen in Takayasu arteritis. Heart Vessels Suppl 7:116-119

34. Khraishi MM, Gladman DD, Dagenais P, Fam AG, Keystone EC (1992) HLA antigens in North American patients with Takayasu arteritis. Arthritis Rheum 35:573-575

35. Mehra NK, Jaini R, Baramurugan A, Kanga U, Prabhakaran D, Jain S, Talwar KK, Sharma BK (1998) Immunogenetic analysis of Takayasu arteritis in Indian patients. Int J Cardiol 66:S127-132

36. Hata A, Noda M, Moriwaki R, Numano F (1996) Angiographic findings of Takayasu arteritis: new classification. Int J Cardiol 54 (Suppl):S155-S163

37. Tyagi S, Kaul UA, Satsangi DK, Arora R (1997) Percutaneous transluminal angioplasty for renovascular hypertension in children: initial and long-term results. Pediatrics 99:44-49

38. Hong CY, Yung YS, Choi JY, Sul JH, Lee KS, Cha SH, Hong YM, Lee HJ, Hong YJ, Sohn KC (1992) Takayasu arteritis in Korean children: clinical report of seventy cases. Heart Vessels 7:91-96

39. Ozen S, Bakkaloglu A, Dusunsel R, Soylemezoglu O, Ozaltin F, Poyrazoglu H, Kasapcopur O, Ozkaya O, Yalcinkaya F, Balat A, Kural N, Donmez O, Alpay H, Anarat A, Mir S, Gur-Guven A, Sonmez F, Gok F, Turkish Pediatric Vasculitis Study Group (2007) Childhood vasculitides in Turkey: a nationwide survey. Clin Rheumatol 26:196-200

40. Shrivastava S, Srivastava RN, Tandon R (1986) Idiopathic obstructive aortoarteritis in children. Indian Pediatr 23:403-410

41. Al abrawi S, Fouillet-Desjonqueres M, David L, Barral X, Cochat P, Cimaz R (2008) Takayasu arteritis in children. Pediatr Rheumatol Online J 6:17

42. Ishikawa K (1988) Diagnostic approach and proposed criteria for the clinical diagnosis of Takayasu's arteriopathy. J Am Coll Cardiol 12:964-972

43. Sharma BK, Jain S, Suri S, Numano F (1996) Diagnostic criteria for Takayasu arteritis. Int J Cardiol 54(Suppl):S141-S147

44. Ozen S, Pistorio A, Filocamo G, Ravelli A, Espada G, Quartier P, Bagga A, Sztajnbok F, Estrella AI, Khubchandani R, Oliveira S, Silva CA, Al-Mayouf S, Bracaglia C, Russo R, Vilca I, Alpigiani MG, Brunner J, Horneff G, Lepore L, Martini A, Ruperto N, for the Pediatric Rheumatology International Trials Organisation (PRINTO) (2009) The 2009 EULAR/PRINTO/PRES criteria for childhood Takayasu arteritis. Ankara 2008. Ann Rheum Dis (in press)

45. Desai MY, Stone JH, Foo T, Hellmann DB, Lima J, Bluemke D (2005) Delayed contrast-enhanced MRI of the aortic wall in Takayasu arteritis: initial experience. AJR Am J Roentgenol 184:1427-1431 
46. Sueyoshi E, Sakamoto I, Uetani M (2006) MRI of Takayasu's arteritis: typical appearances and complications. AJR Am J Roentgenol 187:W569-W575

47. Tann OR, Tulloh RM, Hamilton MC (2008) Takayasu's disease: a review. Cardiol Young 18:250-259

48. Henes JC, Müller M, Krieger J, Balletshofer B, Pfannenberg AC, Kanz L, Kötter I (2008) [18F] FDG-PET/CT as a new and sensitive imaging method for the diagnosis of large vessel vasculitis. Clin Exp Rheumatol 26(3 Suppl 49):S47-S52

49. Tripathy NK, Gupta PC, Nityanand S (2006) High TNF- $\alpha$ and low IL-12 producing $\mathrm{T}$ cells characterize active disease in Takayasu's arteritis. Clin Immunol 118:154-158

50. Chauhan SK, Tripathy NK, Sinha N, Nityanand S (2006) T-cell repertoire of circulating gamma delta T-cells in Takayasu's arteritis. Clin Immunol 118:243-249

51. Verma DK, Tripathy NK, Verma NS, Tiwari S (2005) Interleukin12 in Takayasu's arteritis: plasma concentrations and relationship with disease activity. J Rheumatol 32:2361-2363

52. Park MC, Lee SW, Park YB, Lee SK (2006) Serum cytokine profiles and their correlations with disease activity in Takayasu's arteritis. Rheumatology 45:545-548

53. Rodríguez-Osorio X, Blanco M, Arias S, Castillo J (2008) Biomarkers and PET for assessing the activity of Takayasu's arteritis. Neurologia 23:329-332

54. Hoffman GS, Leavitt RY, Kerr GS, Rottem M, Sneller MC, Fauci AS (1994) Treatment of glucocorticoid-resistant or relapsing Takayasu arteritis with methotrexate. Arthritis Rheum 37:578-582

55. Shelhamer JH, Volkman DJ, Parrillo JE, Lawley TJ, Johnston MR, Fauci AS (1985) Takayasu's arteritis and its therapy. Ann Intern Med 103:121-126

56. Ozen S, Duzova A, Bakkaloglu A, Bliginer Y, Cil BE, Demircin M, Davin JC, Bakkaloglu M (2007) Takayasu arteritis in children: preliminary experience with cyclophosphamide induction and corticosteroids followed by methotrexate. J Pediatr 150:72-76

57. Rodríguez-Hurtado FJ, Sabio JM, Lucena J, Jiménez-Alonso J (2002) Ocular involvement in Takayasu's arteritis: response to cyclophosphamide therapy. Eur J Med Res 28:128-130

58. Shinjo SK, Pereira RM, Tizziani VA, Radu AS, Levy-Neto M (2007) Mycophenolate mofetil reduces disease activity and steroid dosage in Takayasu arteritis. Clin Rheumatol 26:1871-1875

59. Daina E, Schieppati A, Remuzzi G (1999) Mycophenolate mofetil for the treatment of Takayasu arteritis: report of three cases. Ann Intern Med 130:422-426

60. Valsakumar AK, Valappil UC, Jorapur V, Garg N, Nityanand S, Sinha N (2003) Role of immunosuppressive therapy on clinical, immunological, and angiographic outcome in active Takayasu arteritis. J Rheumatol 30:1793-1798
61. Horigome H, Kamoda T, Matsui A (1999) Treatment of glucocorticoid-dependent Takayasu's arteritis with cyclosporine. Med J Aust 170:566

62. Tanaka F, Kawakami A, Iwanaga N, Tamai M, Izumi Y, Aratake K, Arima K, Kamachi M, Nakamura H, Huang M, Ida H, Origuria T, Eguchi K (2006) Infliximab is effective for Takayasu arteritis refractory to glucocorticoid and methotrexate. Int Med 45:313316

63. Hoffman GS, Merkel PA, Brasington RD, Lenschow DJ, Liang P (2004) Anti-tumor necrosis factor therapy in patients with difficult to treat Takayasu arteritis. Arthritis Rheum 50:2296-2304

64. Matsuyama A, Sakai N, Ishigami M, Hiraoka H, Kashine S, Hirata A, Nakamura T, Yamashita S, Matsuzawa Y (2003) Matrix metalloproteinases as novel disease markers in Takayasu arteritis. Circulation 108:1469-1473

65. Uthman IW, Chaaban H (2006) The use of sildenafil in pediatric Takayasu arteritis. Clin Rheumatol 25:550

66. Sharma S, Saxena A, Talwar KK, Kaul U, Mehta SN, Rajani M (1992) Renal artery stenosis caused by nonspecific arteritis (Takayasu disease): results of treatment with percutaneous transluminal angioplasty. AJR Am J Roentgenol 158:417-422

67. Tyagi S, Gambhir DS, Kaul UA, Verma P, Arora R (1996) A decade of subclavian angioplasty: aortoarteritis versus atherosclerosis. Indian Heart J 48:667-671

68. Maksimowicz-McKinnon K, Clark TM, Hoffman GS (2007) Limitations of therapy and a guarded prognosis in an American cohort of Takayasu arteritis patients. Arthritis Rheum 56:1000 1009

69. Lupi-Herrera E, Sanchez-Torres G, Marcushamer J, Mispireta J, Horwitz S, Vela JE (1977) Takayasu arteritis: clinical study of 107 cases. Am Heart J 93:94-103

70. Dabague J, Reyes PA (1996) Takayasu's arteritis in Mexico: a 38 year clinical perspective through literature review. Int J Cardiol 54:S87-S93

71. Lagneau P, Michel JB, Vuong PN (1987) Surgical treatment of Takayasu disease. Ann Surg 205:157-166

72. Subramanyam R, Joy J, Balakrishnan K (1989) Natural history of aortoarteritis. Circulation 80:429-437

\section{Answers}

1. b

2. $\mathrm{d}$

3. c

4. c 